\title{
Assessment of the effect of borides on the thermodynamic characteristics of heterogeneous systems
}

\author{
Vladimir Arkhipov, Liliya Savelieva, and Pavel Ponomarev* \\ National Research Tomsk State University, Tomsk, Russia
}

\begin{abstract}
The possibility of creating high-energy materials with increased ecological purity of combustion products based on a mixed oxidizer (ammonium nitrate, ammonium perchlorate), and inorganic fuel (boron, diboride or aluminum polyboride) is shown.
\end{abstract}

\section{Introduction}

Increasing of the requirements for the environmental cleanliness of combustion products of high-energy materials required the development of fuel systems with a minimum content of chlorine compounds in gaseous combustion products. [7,6].

One of the directions of possible hydrogen chloride $(\mathrm{HCl})$ reduction in combustion products of high-energy materials (HEM) is the replacement of the regular oxidizer of (ammonium perchlorate) with ammonium nitrate. However, nitrate formulations are characterized by a smaller unit impulse, a lower burning rate and longer fluid system ignition delay times. At present, mixed oxidizers (perchlorate and ammonium nitrate) and new metal combustibles, boron (B) and borides, mainly aluminum borides $\left(\mathrm{AlB}_{2}\right.$ and $\left.\mathrm{AlB}_{12}\right)$ are used to increase the energy characteristics of the HEM. [4, 5, 8].

In the literature, data on the optimal ratio of ammonium nitrate (NA) and ammonium perchlorate (PA) components in a mixed oxidant are not found, allowing a single impulse of nitrate HEM to be increased in the combustion products, at a minimum content of $\mathrm{HCl}$, making it closer to the characteristics of perchlorate compounds. The literature also does not show the advantage of aluminum (Al) compared to boron and aluminum borides. $[1,2]$.

The thermodynamic characteristics of HEM containing a mixed oxidant (NA + PA), where the maximum mass fraction of PA is 0.5 is estimated. $\mathrm{Al}$ and $\mathrm{B}$, as well as $\mathrm{AlB}_{2}$ and $\mathrm{AlB}_{12}$ borides based on them, were considered as metallic combustibles.

The aim of the work is to find the optimal composition of a HEM with a single pulse of at least $2500 \mathrm{~m} / \mathrm{s}$ and a minimum content of hydrogen chloride in gaseous combustion products based on the results of calculations of the thermodynamic characteristics.

${ }^{*}$ Corresponding author: pahans-94@mail.ru 
Calculations were carried out for systems with an excess of an oxidizer coefficient equal to 0.5 , containing $15 \% \mathrm{Al}, \mathrm{B}$ and borides $\mathrm{AlB}_{2}$ and $\mathrm{AlB}_{12}$ as metal fuel. The result of the work is the selection of the optimal compositions of the HEM for experimental research.

\section{Results of thermodynamic calculations}

In the work, the characteristics of 35 different HEM compositions were calculated using the "Astra-4" software complex [3], differing in the composition of the mixed oxidant and the nature of the metallic combustible. Calculations of the effectiveness of the influence of the metallic fuel nature on the specific impulse are shown in Fig. 1, as well as on the $\mathrm{HCl}$ content in the combustion products (Fig. 2).

Here 1 is the efficiency of the influence of $\mathrm{Al}, 2$ is the efficiency of the influence of $\mathrm{B}, 3$ is the efficiency of the effect of $\mathrm{AlB}_{2}, 4$ is the efficiency of the influence of $\mathrm{AlB}_{12}$ on the thermodynamic characteristics of the HEM.

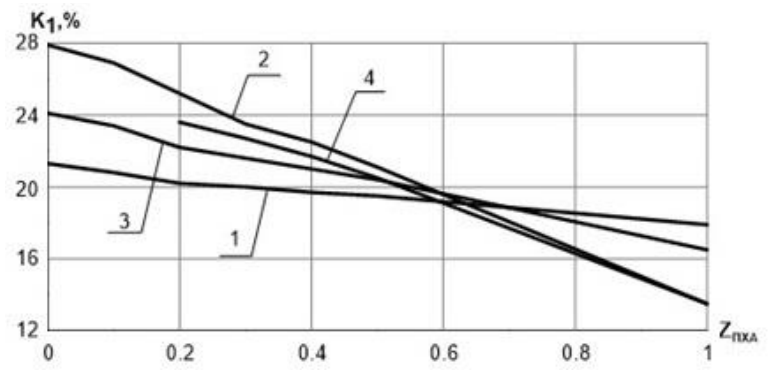

Fig.1. Effectiveness of the influence of the metallic fuel nature on the specific impulse value.

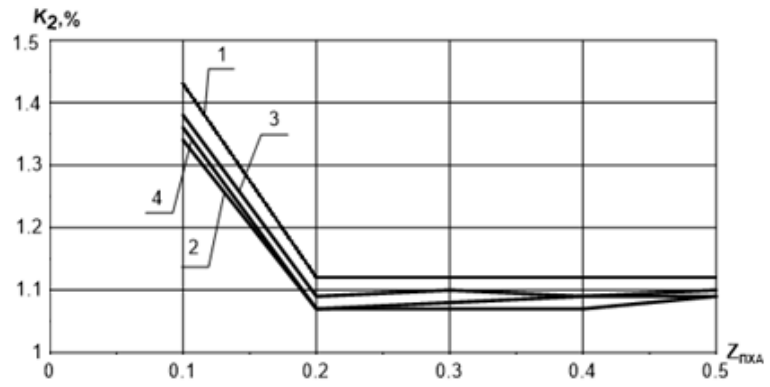

Fig.2. Effectiveness of the influence of the metallic fuel nature on the content of $\mathrm{HCl}$ in combustion products.

The efficiency coefficients $K_{l}$ and $K_{2}$ were calculated using the following formulas:

$$
K_{1}=\frac{I}{I_{0}}, \quad K_{2}=\frac{C_{0}}{C},
$$

where $K_{I}$ is the efficiency of the metallic fuel effect on the specific impulse, $I$ is the specific impulse of the metallized HEM, $I_{0}$ is the specific impulse of the nonmetallic systems, $K_{2}$ is the efficiency of the metallic fuel effect on the $\mathrm{HCl}$ content, $C$ is the $\mathrm{HCl}$ content in the combustion products of metallized HEM, $C_{0}$ - content of $\mathrm{HCl}$ in combustion products of nonmetallic HEM.

The mass fraction of PCA in the mixed oxidant is 


$$
z_{P A}=\frac{m_{P A}}{m_{P A}+m_{N A}}
$$

It follows from Fig. 1 that the efficiency of metals is affected by the composition of the oxidizer of the fluid system, in such a manner for systems containing the initial ammonium perchlorate as an oxidizer, the efficiency of metals decreases in a number:

$$
\mathrm{Al}>\mathrm{AlB}_{2}>\mathrm{AlB}_{12}=\mathrm{B} \text {, }
$$

And with an oxidizer-ammonium nitrate, the efficiency of metals varies in a series:

$$
\mathrm{B}>\mathrm{AlB}_{12}>\mathrm{AlB}_{2}>\mathrm{Al} \text {. }
$$

The second regularity of the change in the efficiency of the metals effect is also valid for a BEM on a mixed oxidizer containing not more than $30 \%$ of PA. A further increase in the content of PA leads to a decrease in the effect of metals on the value of the specific impulse. One of the possible causes of changes in the efficiency of inorganic fuels is the temperature level in the combustion chamber (Table. 1).

Table 1. HEM characteristics.

\begin{tabular}{|c|c|c|c|c|c|}
\hline \multirow{2}{*}{ Oxidizer } & \multirow{2}{*}{ Characteristics } & \multicolumn{4}{|c|}{ Value of characteristics HEM } \\
\cline { 3 - 6 } & & $\mathrm{Al}$ & $\mathrm{AlB}_{2}$ & $\mathrm{AlB}_{12}$ & $\mathrm{~B}$ \\
\hline \multirow{2}{*}{$\mathrm{PA}$} & $I, \mathrm{sec}$ & 268.3 & 265.8 & 260.9 & 259 \\
\cline { 2 - 6 } & $T, \mathrm{~K}$ & 3045 & 2845 & 2624 & 2582 \\
\hline \multirow{2}{*}{$\mathrm{NA}$} & $I, \mathrm{sec}$ & 256.9 & 260.1 & 264.2 & 265.7 \\
\cline { 2 - 6 } & $T, \mathrm{~K}$ & 2655 & 2532 & 2427 & 2431 \\
\hline
\end{tabular}

The effectiveness of the boron and borides influence increases when used in compositions with a combustion product temperature not exceeding $2500 \mathrm{~K}$.

It can be seen from Fig. 2 that the $\mathrm{HCl}$ content in the combustion products of the HEM is directly proportional to the amount of ammonium perchlorate in the mixed oxidant. Therefore, to solve the problem, the choice of a mixed oxidizer is limited by the content of ammonium perchlorate not more than $30 \%$. It should be noted that the injection of the metal somewhat reduces the content of gaseous $\mathrm{HCl}$ in the combustion products in comparison with the nonmetallic compositions. A similar effect is probably due to the formation of chlorine-containing compounds with the metal $\mathrm{AlOHCl}_{2}, \mathrm{AlCl}_{2}$, and $\mathrm{BCl}_{3}$, $\mathrm{BCl}_{2}$, and others. The effect of lowering the $\mathrm{HCl}$ content is more pronounced when injected as a metallic combustible aluminum compared to the boron and borides.

\section{Conclusion}

Analysis of the calculated data showed that the greatest effect of metallic fuel injection both on the value of the specific impulse and on the content of $\mathrm{HCl}$ in combustion products is manifested for systems containing no more than $30 \%$ of PA in the mixed oxidant. The greatest decrease in $\mathrm{HCl}$ in combustion products occurs when the oxidizer contains $10 \%$ PA. It should be pointed out, that the effectiveness of the $\mathrm{Al}$ influence on the reduction of $\mathrm{HCl}$ in combustion products is just over than that of boron and borides $\mathrm{AlB}_{2}$ and $\mathrm{AlB}_{12}$. The efficiency of boron and borides depends almost not at all on their composition. The calculated data allow us to estimate the interval of PA content in a mixed oxidant and to choose the fluid systems for the experimental study.

\section{Acknowledgements}

This work was supported financially by the Ministry of Education and Science of the Russian Federation in terms of state order, project code 9.9752.2017. 


\section{References}

1. Ya.M. Paushkin Liquid and solid chemical rocket fuels (Science, Moscow, 1978) [in Russian]

2. S. Sarner Chemistry of rocket fuels (World, Moscow, 1969) [in Russian]

3. B.G. Trusov, Modeling of chemical and phase equilibria at high temperatures "Astra-4" version 1.06 (Publishing house of the Moscow State Technical University named after Bauman, Moscow, 1991) [in Russian]

4. M. K. King, Journal of Spacecraft and Rockets, 19 (4), 294 (1982)

5. F. Gorman, Missile technology issues, (1), 41 (1971)

6. Mirković, D., Gröbner, J., Schmid-Fetzer, R. , Fabrichnaya, O., Lukas, H.L., J. Alloys Compd., 384, 168 (2004)

7. A.B. Vorozhtsov, Novel Micro- and Nanofuels: Production, Characterization, and Applications for High-Energy Materials (Springer International Publishing, Switzerland, 2017)

8. Lempert D. B., Power capabilities of Solid rocket fuels with oxidizers based on stressed frames, $98(2000)$ 